\title{
Effect of Heat Treatment on Microstructure of Al4Cu-SiC Composites Consolidated by Powder Metallurgy Technique
}

\author{
A. Wąsik, B. Leszczyńska-Madej, M. Madej, and M. Goły
}

\author{
(Submitted October 22, 2019; in revised form February 8, 2020; published online February 24, 2020)
}

\begin{abstract}
Silicon carbide particles-reinforced Al4Cu composites containing 2.5, 5 and 7.5 wt.\% of reinforcement were fabricated using powder metallurgy (PM) technique. The sintered $\mathrm{Al} 4 \mathrm{Cu}-\mathrm{SiC}$ composites were solution treated for $6 \mathrm{~h}$ at two different temperatures $\left(495\right.$ and $\left.530{ }^{\circ} \mathrm{C}\right)$ and then aged at $180^{\circ} \mathrm{C}$ for various aging periods (4, 12 and $24 \mathrm{~h})$. Effects of heat treatment on the microstructural changes and microhardness were investigated by scanning electron microscope, transmission electron microscope, $x$-ray diffraction and microhardness tests. The results indicate the ceramic particles-reinforced $\mathrm{Al4Cu}$ matrix requires different heat treatment parameters compared to the unreinforced alloy. The applied solution temperature did not allow for thorough dissolution of alloy phases in the matrix material produced by PM route. However, in $\mathrm{Al4Cu}-\mathrm{SiC}$ composites the main strengthening phase $\left(\mathrm{Al}_{2} \mathrm{Cu}\right)$ was uniformly distributed in the matrix. The solid-solution temperature increase affects the reduction in time to reach peak hardness. The highest increment in microhardness by aging treatment was observed for composite with the addition of $5 \mathrm{wt} \%$ of SiC solution treated at $530{ }^{\circ} \mathrm{C}$ for $12 \mathrm{~h}(110 \mathrm{HV0.05})$.
\end{abstract}

Keywords heat treatment, metal-matrix composites (MMCs), microstructure, particle reinforcement

\section{Introduction}

The wide range of applications of light metal-matrix composites (MMCs) has attracted the attention because of their increased mechanical properties. However, it has to be noted that the obtained properties of composite materials are significantly influenced by the chemical composition and the methodology used to consolidate the materials, which enables formulating permanent matrix-reinforcement bonding, and more importantly by the microstructural evolution associated with applied heat treatment procedure (Ref 1$)$.

One of the methods for improving the mechanical properties of aluminum alloys is heat treatment, which has a strong influence on the microstructure of the composites (Ref 2). Al$\mathrm{Cu}$ alloys with a copper content up to approximately $5 \%$ are intended for heat treatment (precipitation hardening), as the copper is one of the most important aluminum alloy elements due to its high solubility and strengthening effect. Precipitation hardening, also known as age hardening, is the heat treatment of aluminum alloys involving solution treatment, quenching

A. Wạsik and B. Leszczyńska-Madej, Department of Materials Science and Non - Ferrous Metals Engineering, Faculty of Non Ferrous Metals, AGH University of Science and Technology, Mickiewicza 30 Av., 30-059 Cracow, Poland; and M. Madej and M. Goly, Department of Physical and Powder Metallurgy, Faculty of Metals Engineering and Industrial Computer Science, AGH University of Science and Technology, Mickiewicza 30 Av., 30-059 Cracow, Poland. Contact e-mail: anna.wasik@agh.edu.pl. and aging at both room (natural aging) and elevated (artificial aging) temperatures (Ref 3). The strengthening effect of the material subjected to precipitation hardening results from the formation of extremely fine, uniformly dispersed particles of a second phase within the original phase matrix. The different age-hardening behavior has been nevertheless observed in aluminum matrix composites produced by powder metallurgy. Effect of the addition of ceramic reinforcing phase in aluminum alloy matrix on the aging process behavior requires better understanding. Scientific sources report that on the one hand the rapid hardening of composite materials and attaining peak hardness much earlier has been observed compared to the unreinforced alloy, which could indicate the aging characteristic accelerated with the reinforcement $(\operatorname{Ref} 4,5)$. However, at the same time it has been shown that the presence of ceramic reinforcements leads to a significant retardation in the kinetics of hardening (Ref 6, 7). There are a number of factors influencing the nature of change in kinetics and magnitude of hardening during aging the MMCs, such as chemical composition of the matrix material, size, shape and weight fraction of reinforcement and also the method of processing the composite, not to mention the applied heat treatment parameters $(\operatorname{Ref} 8,9)$.

In light of the above, one of the aims of this work was to investigate the influence of the addition of silicon carbide particles to $\mathrm{Al} 4 \mathrm{Cu}$ matrix on the heat treatment process and the next one was to research the effect of variable heat treatment parameters on microstructural changes and mechanical properties of $\mathrm{Al} 4 \mathrm{Cu}-\mathrm{SiC}$ composites.

\section{Experimental Procedure}

The matrix alloy powders were $\mathrm{Al}$ and $\mathrm{Cu}$ with weight fraction of $\mathrm{Cu}$ of $4 \%$. The average particle size of aluminum powder, produced by argon gas atomization, was below $63 \mu \mathrm{m}$. 
(The fractions of the powder are as follows: above $63 \mu \mathrm{m}-5 \%$, in the rage of $32-63 \mu \mathrm{m}-45-70 \%$ and below $32 \mu \mathrm{m}$ - the rest.) The electrolytic copper powder had an average size of $<40 \mu \mathrm{m}$. The weight fraction of $\mathrm{SiC}$ particles in the composite material was $2.5,5$ and $7.5 \%$, and the average particle size ranged below $2 \mu \mathrm{m}$. The morphology of raw material powders used in this study is presented in Fig. 1. Aluminum powder is characterized by an elongated and irregularly shaped particle with a relatively smooth surface. Copper powder has the dendritic shape, which is characteristic for electrolytic manufacturing. Silicon carbide particles are characterized by an angular shape. $\mathrm{Al} 4 \mathrm{Cu}$ matrix alloy composites were prepared by blending pure aluminum powder and pure copper powder with silicon carbide particles in appropriate mass proportions of the reinforcing phase to the matrix material for $30 \mathrm{~min}$ in a Turbula $\mathrm{T} 2 \mathrm{~F}$ mixer. Then, the mixed powders were put into a rigid die and pressed at room temperature under a pressure of $300 \mathrm{MPa}$ on a single-action compaction press. The matrix walls were lubricated with glycerin to prevent powder adhesion to the matrix. The obtained green bodies were the cuboid shape $(4.5 \times 5 \times 40 \mathrm{~mm})$. The compacts were sintered under nitrogen atmosphere at $600{ }^{\circ} \mathrm{C}$ for $1 \mathrm{~h}$. The not-heat-treated sinters were slowly cooled in the furnace cooler at a rate of about $40{ }^{\circ} \mathrm{C}$.

The sintered Al4Cu-SiC composite samples subjected to heat treatment were solution treated at 495 and $530{ }^{\circ} \mathrm{C}$ for $6 \mathrm{~h}$, water quenched and then aged at $180{ }^{\circ} \mathrm{C}$ for various aging periodic times: 4,12 and $24 \mathrm{~h}$. The main purpose of solution treatment is to dissolve the precipitates and obtain a homogeneous solution, and then preserve the solid solution by rapidly cooling to a lower temperature. The heat treatment parameters recommended for the peak hardening (T6 treatment) for alloys of similar compositions mentioned elsewhere (Ref 3, 8, 10,11) consist of solution treatment in the temperature ranging from 495 to $530{ }^{\circ} \mathrm{C}$ and aging treatment at $180{ }^{\circ} \mathrm{C}$. The selected conditions of solution treatment represent two extreme temperatures and thus expected different degrees of dissolution of solute in the matrix. This action is intended to examine the effect of heat treatment procedure on microstructure and mechanical properties of tested materials. Age-hardening behavior of the $\mathrm{Al} 4 \mathrm{Cu}$ matrix and $\mathrm{Al} 4 \mathrm{Cu}-\mathrm{SiC}$ composites was analyzed by measuring the microhardness of the samples at different solution temperatures and aging times using a Vickers hardness testing machine. Vickers microhardness was measured on mirror-shine polished sample surfaces using a Shimadzu HMV-G microhardness tester with a Vickers indenter. A load of $100 \mathrm{~g}$ was applied in the microhardness measurement. Microstructure and morphology of precipitants in $\mathrm{Al} 4 \mathrm{Cu}$ alloy matrix without and with the addition of $\mathrm{SiC}$ particles at each stage of heat treatment were observed with a Schottky electron gun scanning electron microscope with Thermo Scientific NORAN System 7 x-ray microanalysis system (EDS)-Hitachi SU-70. Samples for microstructure examinations were mechanically ground and polished with diamond paste and colloidal suspension of $\mathrm{SiO}_{2}$. The microstructure was additionally examined by transmission electron microscopy (TEM) using a JEOL JEM 2010 ARP microscope. The thin foils for electron transmission observations were prepared by ion milling. Information about the phase composition was provided by the EDS and x-ray diffraction (XRD) analyses (Bruker, Co K $\alpha=1$. $97 \AA$ radiation).

\section{Results and Discussion}

\subsection{Density of Sinters}

Figure 2 presents the density measurements using Archimedes method of not-heat-treated sinters of Al4Cu matrix and composite materials. The highest relative density was characterized by the matrix material ( $96.99 \%$ of theoretical density). The addition of silicon carbide particles resulted in a decrease in the relative density, which remains constant regardless of the weight fraction of reinforcing phase and ranges from 95.87 to $94.99 \%$ of the theoretical density.

As it results from the above-presented values of Archimedes density powder metallurgy, processed composites are characterized by a high degree of compaction and the porosity not exceeding $6 \%$. However, it is expected that a further increase in the content of the strengthening phase (above $7.5 \mathrm{wt} . \%$ of $\mathrm{SiC}$ ) will result in a decrease in the degree of compaction of the material. It is associated with porosity at the interface between $\mathrm{SiC}$ particles and matrix indicating weak bonding formed during consolidation using conventional powder metallurgy process. Alloyed powders are less prone to compaction than pure metal powders. Thus, the increase in weight fraction of strengthening phase in the form of $\mathrm{SiC}$ particles in $\mathrm{Al} 4 \mathrm{Cu}$ matrix hinders the achievement a high degree of compaction and resulted in higher porosity. Moreover, the research conducted by the authors (Ref 11) shows that the porosity influences for the aging kinetics, as the porous materials aged slower than the dense materials.

\subsection{Microstructural Observation}

Figure 3 shows the micrograph of matrix material and composite material with the addition of $5 \mathrm{wt} . \%$ of $\mathrm{SiC}$ after sintering process. The microstructure consists of regular shape of aluminum grains and locally scare pores. Additionally, in
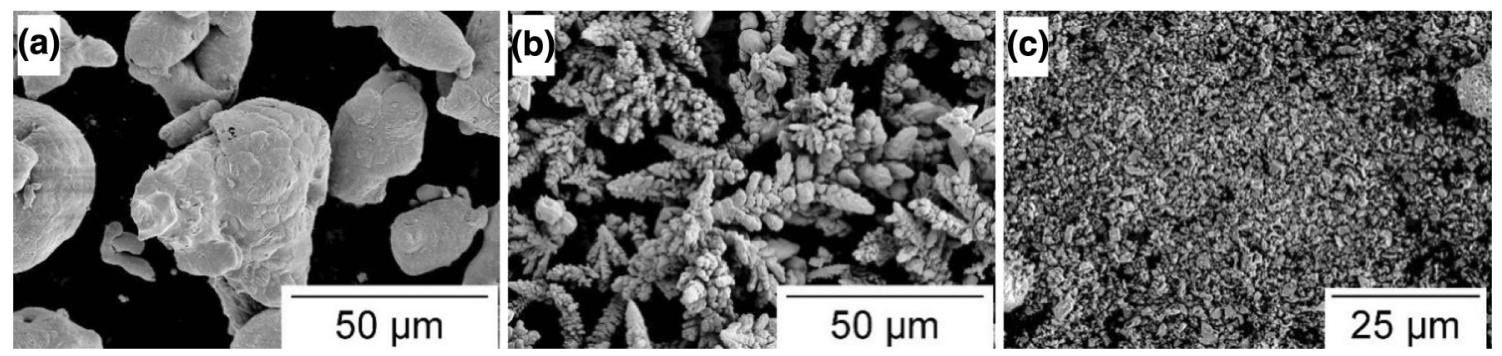

Fig. 1 SEM micrographs of powders: (a) aluminum, (b) copper, (c) $\mathrm{SiC}$ 
composites with the addition of strengthening phase, the silicon carbide particles are visible on grain boundaries. In the microstructure of non-heat-treated matrix materials as well as composite materials, the primary grain boundaries are revealed by the white continuous network spread along the Al powder particles. The analysis of EDS in Fig. 4 indicated high content of copper in these areas which are alloy phases formed during slow cooling after sintering process. The composition of the precipitates is corresponding to the composition of the $\mathrm{Al}_{2} \mathrm{Cu}$ phase (points 1, 2 and 3). The strengthening caused by coarser $\mathrm{Al}_{2} \mathrm{Cu}$ precipitates located on the grain boundaries is insignificant. Furthermore, large hard particles on the grain boundaries cause a significant deterioration of fracture toughness (Ref 12). XRD pattern of composite with the addition of $5 \mathrm{wt} . \%$ of $\mathrm{SiC}$ is shown in Fig. 5. It can be confirmed that the composite

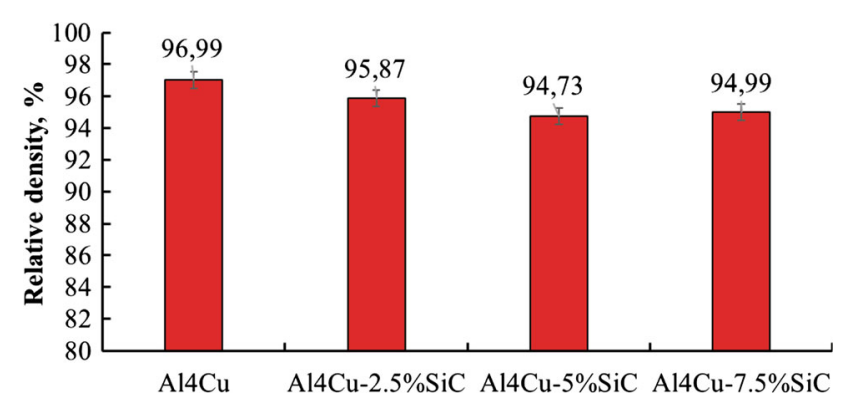

Fig. 2 Variation of Archimedes density of non-heat-treated sinters materials are mainly composed of $\mathrm{Al}$ matrix, $\mathrm{SiC}$ particles and $\mathrm{Al}_{2} \mathrm{Cu}$ phase and as the sintering process was carried out under nitrogen atmosphere, aluminum nitride was formed. An advantage of sintering aluminum and its alloy under nitrogen atmosphere is the formation of aluminum nitride which is acting as an additional strengthening factor and in addition penetrating into the pores increases the degree of compaction. The formation of aluminum nitride is an exothermic reaction which may occur if nitrogen gains a direct contact with the freshly exposed aluminum surface (Ref 13).

Copper is one of the most important aluminum alloy elements due to its high solid solubility in aluminum and strengthening effect. The alloy with the content of $4 \%$ of copper at thermodynamic equilibrium at ambient temperature is

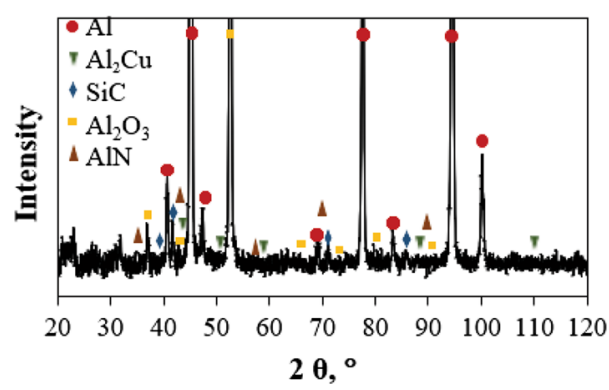

Fig. 5 X-ray diffraction pattern of the Al4Cu-5 wt.\% of $\mathrm{SiC}$ composite material
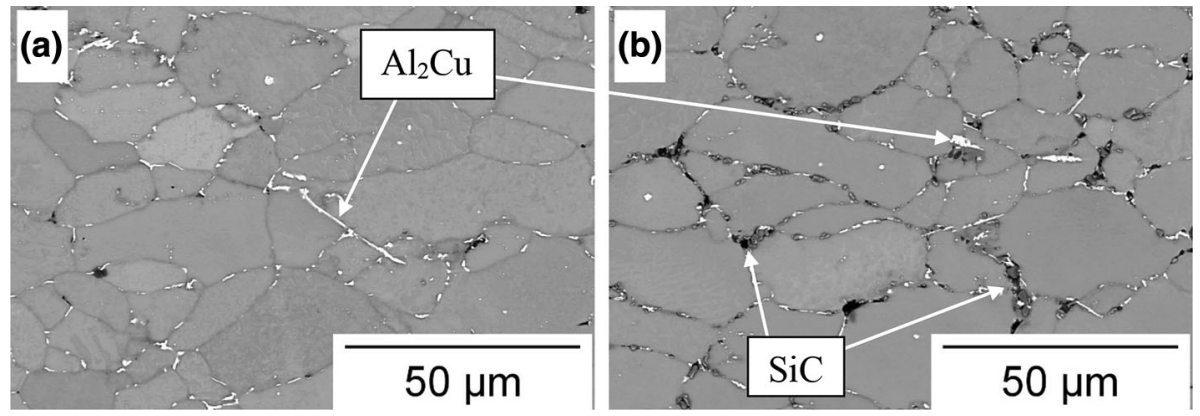

Fig. 3 SEM microstructure of PM: (a) Al4Cu alloy, (b) Al4Cu-5 wt.\% of SiC

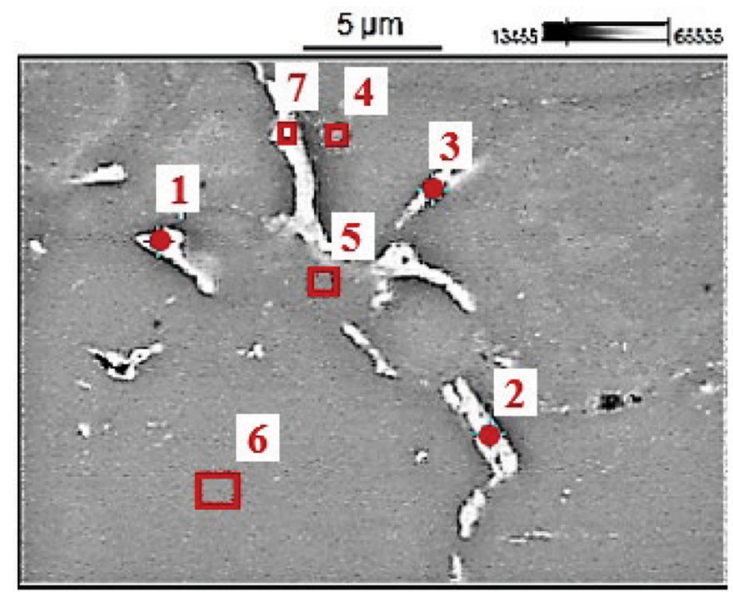

\begin{tabular}{|c|c|c|c|c|}
\hline No & $\begin{array}{c}O \\
w t \%\end{array}$ & $\begin{array}{c}A l, \\
w t \%\end{array}$ & $\begin{array}{c}F e, \\
w t \%\end{array}$ & $\begin{array}{c}C u, \\
w t \%\end{array}$ \\
\hline$p t 1$ & 1 & 72 & - & 27 \\
\hline pt 2 & 3 & 65 & 8 & 24 \\
\hline pt 3 & 1 & 76 & - & 23 \\
\hline pt 4 & 5 & 93 & - & 2 \\
\hline pt 5 & 1 & 91 & 1 & 7 \\
\hline$p t 6$ & - & 95 & - & 5 \\
\hline$p t 7$ & 5 & 74 & 5 & 16 \\
\hline
\end{tabular}

Fig. 4 Chemical analysis carried out in micro-regions of as-sintered $\mathrm{A} 14 \mathrm{Cu}$ matrix, SEM 
composed of two phases: a matrix consisting of solid solution $\alpha$ and intermetallic phase $\theta\left(\mathrm{Al}_{2} \mathrm{Cu}\right)$. The purpose of solution heat treatment is to dissolve the $\theta$-phase particles and obtain a uniform solid-solution structure. The maximum solid solubility in aluminum matrix of the copper decreases with temperature dropping. While the solid solubility of copper at $550{ }^{\circ} \mathrm{C}$ is $5.65 \%$, at ambient temperature the solid solubility of copper in aluminum drops to $0.2 \%$. Therefore, in solution treatment process the second soluble phase $\theta$ gradually dissolves into the aluminum matrix as solution temperature rises (Ref 3 ).

Figure 6 shows SEM images of matrix material $\mathrm{Al} 4 \mathrm{Cu}$ with different heat treatment processes. There is a significant amount of micron coarse intermetallic phases formed inside the grain and on grain boundaries both after solution at 495 and $530{ }^{\circ} \mathrm{C}$. It indicates that the applied solution temperature in the first instance $\left(495^{\circ} \mathrm{C}\right)$ is too low, as in the microstructure there are still a lot of micron particles remaining in the matrix. Precipitate particles of alloy phase are in the form of coagulants with high content of copper. Phase precipitations are accompanied by a reduction in the concentration of dissolved copper atoms in the matrix. As the solution temperature increases, the alloy phase particles would be expected to dissolve, and as a result, the solid solution with the maximum degree of supersaturation would be obtained. However, when the solution temperature reaches $530{ }^{\circ} \mathrm{C}$, alloy phases re-emerge as a result of too high solution temperature. Comparing the x-ray diffraction pattern obtained for the tested solution temperature, it was found that an increase in solution temperature caused the size of alloy phases to become smaller and their number to become greater (Fig. 7). Comparing the x-ray diffraction patterns of the $\mathrm{Al} 4 \mathrm{Cu}$ alloy solution treated at different temperatures, it was found the peak intensity corresponding to the $\mathrm{Al}_{2} \mathrm{Cu}$ phase is higher in the alloy previously subjected to solution treatment at $530{ }^{\circ} \mathrm{C}$, indicating a higher number of these precipitates, while the peak width corresponding to $\mathrm{Al}_{2} \mathrm{Cu}$ phase is higher after solution treatment at $495{ }^{\circ} \mathrm{C}$, indicating a larger size of precipitates. Apart from the growth of the alloy phases previously formed on grain boundaries, new, discoid-shaped precipitate particles of $\mathrm{Al}_{2} \mathrm{Cu}$ phase are formed. The microstructure of the matrix after aging, which has been pre-treated at $495{ }^{\circ} \mathrm{C}$, shows a similar character as after solution treatment. An increase in the time of aging favors impoverishment of the precipitate formation in areas adjacent to the grain boundaries (Fig. 6c). The width of these areas is affected by the rate of solution and aging temperature. The increase in the width of zones free from precipitates of $\Theta$ phase is caused by applying a lower cooling rate in the solution treatment and a higher aging temperature. The presence of zones free of precipitates on both sides of the grain boundary can be explained by the phenomenon of micron particles of alloy phase growth on grain boundaries, which by increasing their size cause "drawing-in" dissolved atoms from areas adjacent to the grain boundary (Ref 14). An increase in the solution temperature to $530{ }^{\circ} \mathrm{C}$ resulted in a decrease in the size of the alloy phases in the matrix subjected to the aging hardening at different time periods. With increasing aging time,

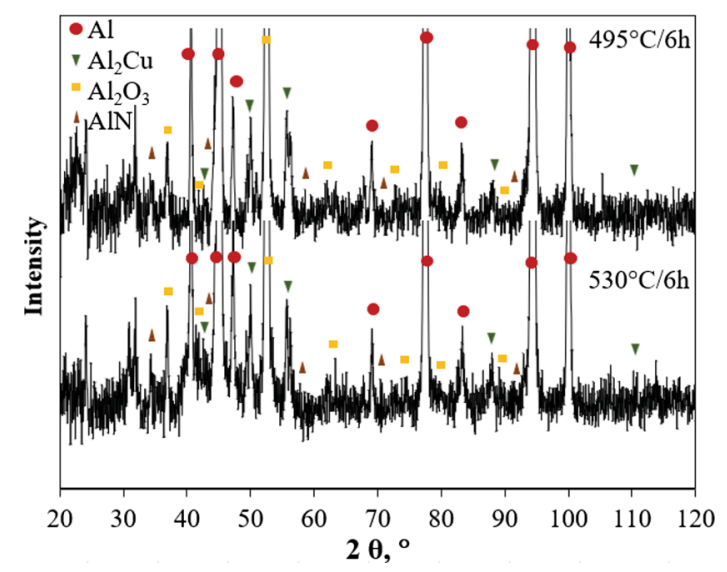

Fig. 7 X-ray diffraction pattern of the $\mathrm{A} 14 \mathrm{Cu}$ solution treated at different temperatures
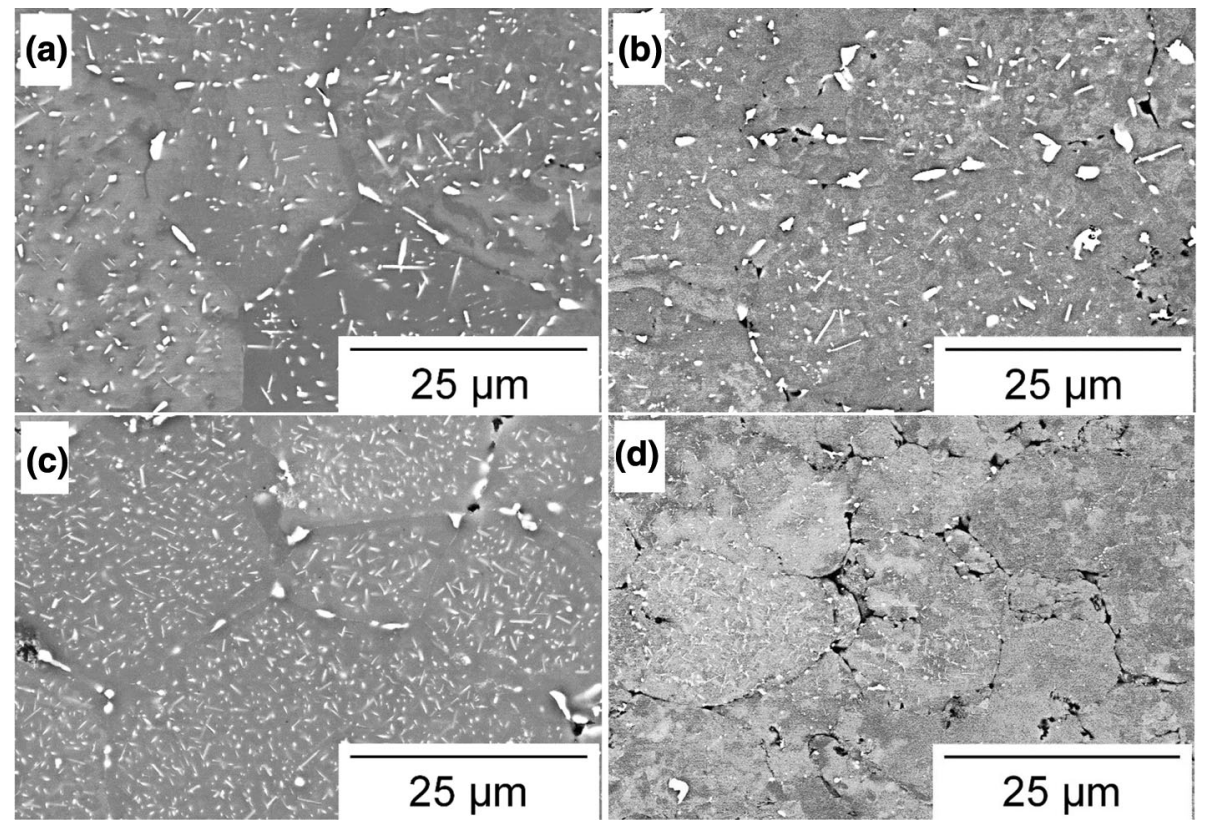

Fig. 6 SEM images of $\mathrm{A} 14 \mathrm{Cu}$ matrix after heat treatment at different temperatures: (a) $495{ }^{\circ} \mathrm{C}$ solution; (b) $530{ }^{\circ} \mathrm{C}$ solution; (c) $495{ }^{\circ} \mathrm{C}$ solution + artificial aging $(24 \mathrm{~h})$; (d) $530{ }^{\circ} \mathrm{C}$ solution $+\operatorname{artificial}$ aging $(24 \mathrm{~h})$ 
the number of precipitates in grains increases. After $24 \mathrm{~h}$ of aging in the microstructure, very fine evenly distributed particles of alloy phase can be observed (Fig. 6d).

There was a difference between the heat-treated microstructure of the matrix material and composite materials reinforced with $\mathrm{SiC}$ particles (Fig. 8). The presence of $\mathrm{SiC}$ strengthening inhibits the precipitation of $\mathrm{Al}_{2} \mathrm{Cu}$ phase which is stopped at the boundaries, mainly on the silicon carbide particles. Therefore, the amount of precipitates of a second phase inside the grain is lower and at the same time their size is finer compared to the matrix material without the addition of ceramic particles. In microstructure of composites, subjected to solution treatment at $495{ }^{\circ} \mathrm{C}$, the precipitations of $\mathrm{Al}_{2} \mathrm{Cu}$ phase located on grain boundaries are visible (Fig. 8a). There were no precipitates inside the grains. Increasing the solution temperature up to $530{ }^{\circ} \mathrm{C}$ caused the $\mathrm{Al}_{2} \mathrm{Cu}$ phase precipitation inside the grain, while the grain boundaries are free of $\mathrm{Al}_{2} \mathrm{Cu}$ precipitate particles (Fig. 8b). However, the amount and size of second phase inside the grain are much smaller compared to that of the $\mathrm{A} 14 \mathrm{Cu}$ matrix subjected to the solution at the same conditions. It indicates that applying solution temperature equal to $530{ }^{\circ} \mathrm{C}$ in solution treatment of composite materials allows for almost complete dissolution of intermetallic phase.

An increase in the aging time to $24 \mathrm{~h}$ of composites previously solution treated at $495{ }^{\circ} \mathrm{C}$ favored precipitation inside the grain fine dispersive precipitates (Fig. 8c). The solution treatment carried out at $530{ }^{\circ} \mathrm{C}$ and aging for $12 \mathrm{~h}$ resulted in precipitation in composite material of needleshaped, alternately arranged second phases. Figure 9 shows the TEM image of the composite material with the addition of 5 wt. \% of $\mathrm{SiC}$ treated through solution at $530{ }^{\circ} \mathrm{C}$ and aging for $12 \mathrm{~h}$. It can be seen there are many nanosized precipitated phases dispersively distributed in the matrix.

The hard ceramic SiC particles introduced into the plastic aluminum alloy matrix increase the strain energy in the periphery of the particles in the matrix. These tendencies may be due to the mismatch in the thermal expansion coefficients of ceramic particles and $\mathrm{Al}$ matrix during solution treatment and contributes to the formation of high dislocation densities at the reinforcement/matrix phase boundary (Ref 15, 16). Thus, dislocations stimulate the increase in hardness as they act as non-uniform nucleation sites in the interface following the age treatment. The residual stress and high dislocation density can lead to formation of excess free vacancies. Enhanced solute diffusivity in the matrix of composites can accelerate the GP zone formation, as the GP zone requires vacancy clusters. The main strengthening phase of $\mathrm{Al}-\mathrm{Cu}$ alloy is $\theta\left(\mathrm{Al}_{2} \mathrm{Cu}\right)$. High dislocation density in the composite matrix provides more nucleation sites for $\theta$ precipitation. The mechanism of strengthening in precipitation hardening consists in impeding the movement of dislocations, which are stopped by incoherent precipitates from a supersaturated solid solution. In TEM images, the phenomenon of dislocation movement inhibition on the precipitated $\mathrm{Al}_{2} \mathrm{Cu}$ phases can be observed (Fig. 9).

Additionally, the aging kinetics will be affected by the presence of porosity at the particulates' interface. The aging kinetics of porous materials is slower than that of the dense materials due to the annihilation of dislocation as a result of the presence of higher porosity. It is associated with the location of $\mathrm{SiC}$ particles in the free space in-between larger grains of the matrix during quenching and thus with the reduction in the magnitude of misfit strains which affects the reduction in the average dislocation density and reduction in the heterogeneous nucleation volume around the particulates. The presence of porosity in the locally formed agglomerations of $\mathrm{SiC}$ particles allows the individual $\mathrm{SiC}$ particles to adapt to the compressive forces acting during quenching and hence reduces the precipitation of strengthening phase through reducing the heterogeneous nucleation sites in the form of dislocations.

\subsection{Age-Hardening Behavior}

In the investigated $\mathrm{Al}-\mathrm{Cu}$ alloy, during age hardening, the precipitation process has the following sequence: GP zone $\rightarrow$
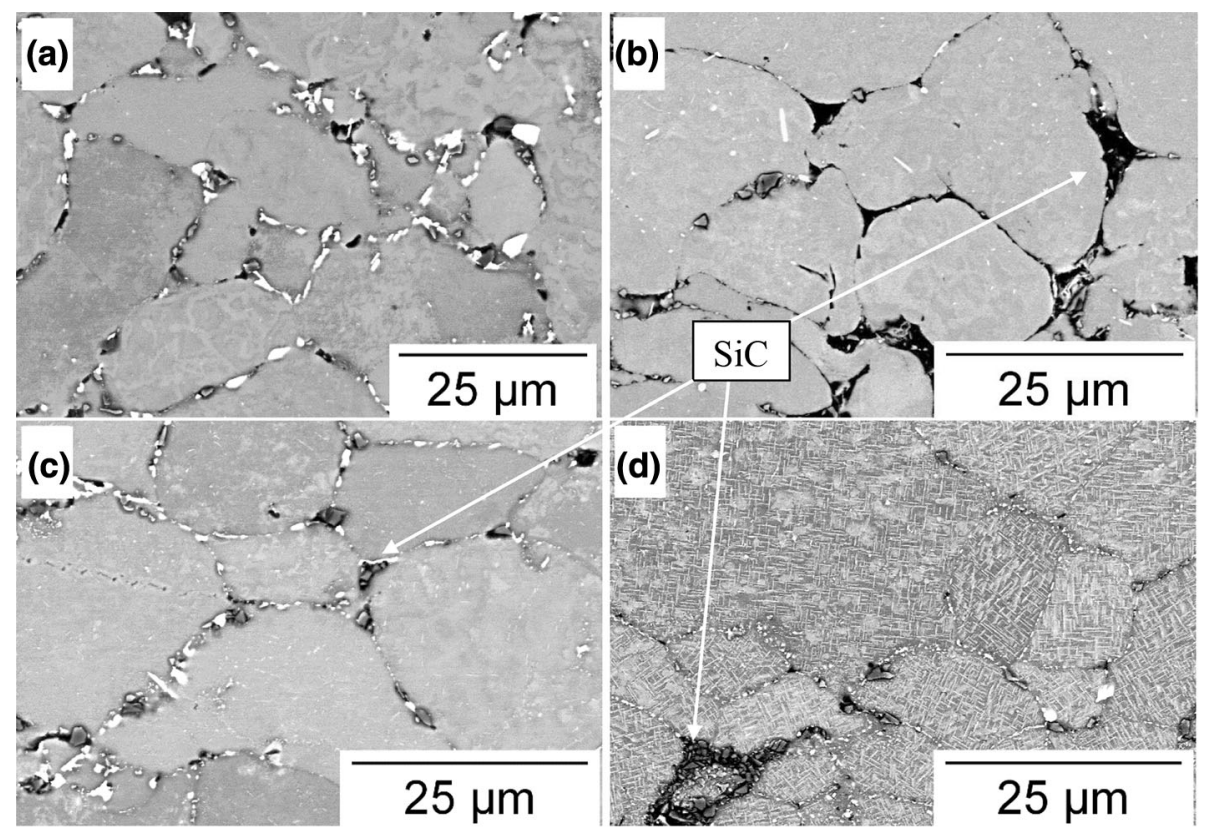

Fig. 8 SEM images of Al4Cu-5 wt.\% of SiC composite after heat treatment at different temperatures: (a) $495{ }^{\circ} \mathrm{C}$ solution; (b) $530{ }^{\circ} \mathrm{C}$ solution; (c) $495{ }^{\circ} \mathrm{C}$ solution + artificial aging $(24 \mathrm{~h})$; d) $530{ }^{\circ} \mathrm{C}$ solution + artificial aging $(24 \mathrm{~h})$ 

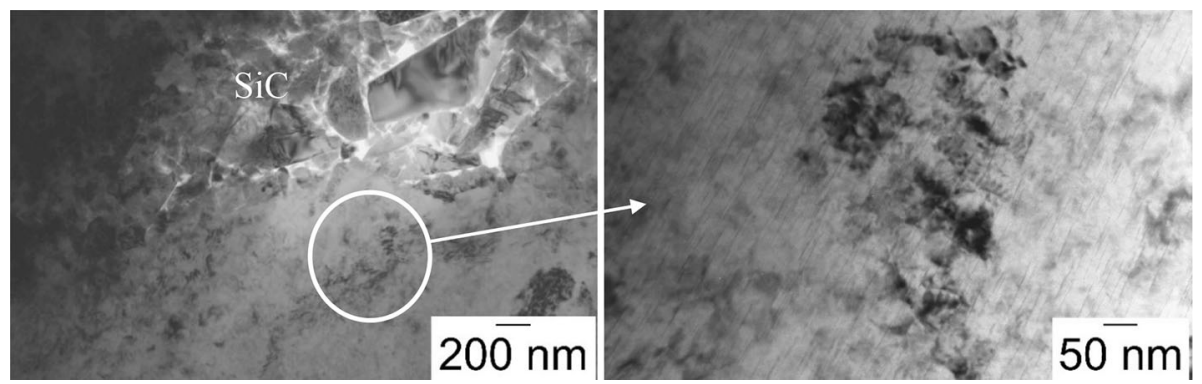

Fig. 9 TEM images of $\mathrm{Al} 4 \mathrm{Cu}-5$ wt.\% of $\mathrm{SiC}$ composite after solution treatment at $530{ }^{\circ} \mathrm{C}$ and artificial aging for $12 \mathrm{~h}$

GPII zone $\left(\theta^{\prime \prime}\right) \rightarrow \theta^{\prime}$ intermediate $\rightarrow \theta\left(\mathrm{Al}_{2} \mathrm{Cu}\right)$ phase (Ref 17). Therefore, metastable precipitated phases are formed before finally forming the equilibrium phase, such as $\mathrm{Al}_{2} \mathrm{Cu}$. The most effective, from the point of view of increasing hardness, are the GPII zone and $\theta^{\prime}$ intermediate (Ref 18, 19). The precipitation of the stable $\theta$ phase decreases hardness (over aging) (Ref 3, 20). The addition of $\mathrm{SiC}$ reinforcement into aluminum alloy matrix generally accelerates the aging kinetics but does not change its aging precipitation process. Introducing the $\mathrm{SiC}$ particles to the aluminum alloy generates additional vacancy sinks due to formation of matrix/reinforcement interfaces. However, at the same time during aging the presence of $\mathrm{SiC}$ particles inhibits the precipitation of $\mathrm{Al}_{2} \mathrm{Cu}$ phase from the solution, as it is pinned at the grain boundaries, mainly on $\mathrm{SiC}$ particles. Figure 10(a) and (b) shows the aging plots for the matrix material and composites previously solution treated at 495 and $530{ }^{\circ} \mathrm{C}$, respectively. Additionally, Table 1 presents the values that correspond to aging response of $\mathrm{Al}-\mathrm{Cu}-$ $\mathrm{SiC}$ composites.

The results of microhardness measurement on each stage of heat treatment indicate that the applied solution temperature $\left(495,530{ }^{\circ} \mathrm{C}\right)$ did not allow for solid-solution strengthening of the $\mathrm{Al} 4 \mathrm{Cu}$ alloy produced by the powder metallurgy technique. The coarser $\mathrm{Al}_{2} \mathrm{Cu}$ phase formed in microstructure after solution treatment did not fulfill the strengthening function. The aging process, regardless of the aging time, also did not result in a significant microhardness change. The heat treatment temperature may be influenced by the presence of pores and higher content of oxygen in the microstructure of sinters, compared to the alloys produced under traditional conditions. The slower kinetics of aging in the matrix material is attributed to the lower concentration of vacancies and dislocation density. Instead, the composite materials seem to respond well to agehardening process. For the composite materials with the addition of lower content of strengthening phase (2.5 wt.\% of $\mathrm{SiC}$ ), both solution treated at 495 and $500{ }^{\circ} \mathrm{C}$, the incubation period (time for the reaching highest hardness) is found to be much shorter (after $4 \mathrm{~h}$ ) compared to that of composite materials with the content of SiC particles above 2.5 wt.\%. For the composites with the addition of 5 and $7.5 \mathrm{wt} . \%$ solution treated at $495{ }^{\circ} \mathrm{C}$ the maximum peak microhardness was recorded after $24 \mathrm{~h}$ of aging, while after solution treatment at $530{ }^{\circ} \mathrm{C}$ after $12 \mathrm{~h}$ of aging. Differences in the aging response of $\mathrm{A} 14 \mathrm{Cu}$ alloy and composites can be found in the applied method of manufacturing. Both materials were produced by powder metallurgy route. Due to the strong affinity for oxygen, aluminum particles are covered with a thin oxide layer. Therefore, obtained materials contained an appreciable amount of oxide inclusions. The presence of oxide inclusions and
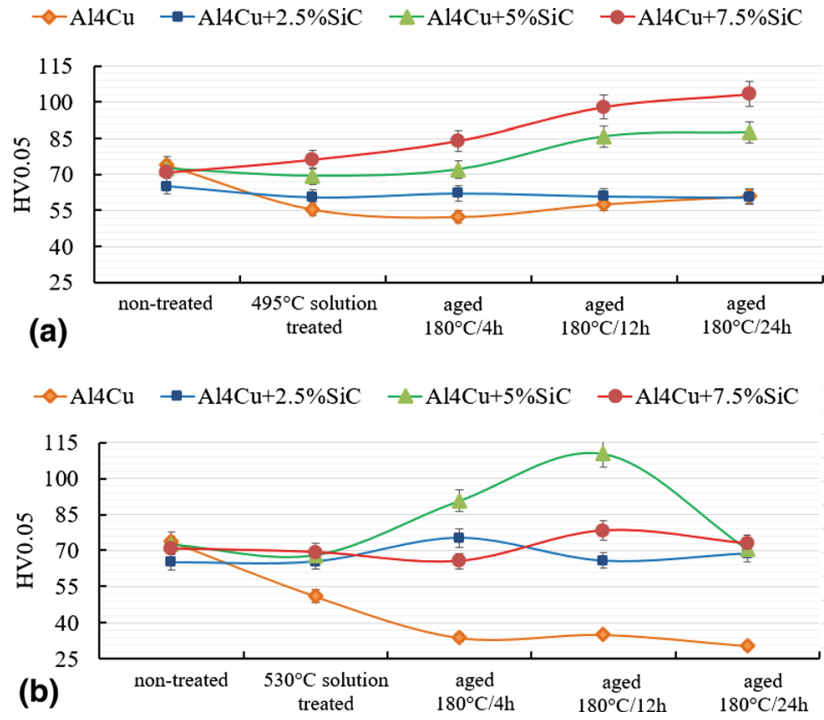

Fig. 10 Age-hardening behaviors of the composites: (a) $495{ }^{\circ} \mathrm{C}$ solution; (b) $530{ }^{\circ} \mathrm{C}$ solution

oxide-matrix boundaries, but also increased specific surface area, resulting from grain refinement of powder metallurgyprocessed materials, is likely to reduce vacancy concentration and consequently suppresses GP zone formation. On the other hand, due to the linear expansion coefficient difference between reinforcement and matrix material, during quenching from the solution temperature, a large amount of plastic strain develops. This strain is accommodated by the high density of dislocation generation in the matrix of composite compared to unreinforced $\mathrm{Al} 4 \mathrm{Cu}$ alloy. High density of dislocation also has an influence on the relatively poor vacancy. However, the generated quenching stress might cause the formation of excess free vacancies needed for nucleation of GP zones (Ref 3, 8, 11).

The aging of the composite with the addition of $2.5 \mathrm{wt} . \%$ of $\mathrm{SiC}$ did not result in major change in microhardness when the aging period increases. In all cases, the microhardness remained at a similar level. A different dependence of microhardness changes was observed in composites with a higher content of reinforcement. It can be seen that microhardness increases as the aging time is extended up to $24 \mathrm{~h}$. Among composites solution treated at $495{ }^{\circ} \mathrm{C}$, the highest microhardness was characterized by the composite with the addition of $7.5 \mathrm{wt} . \%$ of $\mathrm{SiC}$ after $24 \mathrm{~h}$ of aging (103 HV0.05). Increasing the solution temperature up to $530{ }^{\circ} \mathrm{C}$ resulted in obtaining peak microhardness earlier-after $12 \mathrm{~h}$ of aging, and for the composite reinforced by 5 wt. $\%$ of $\mathrm{SiC}$, microhardness increased to 110 


\begin{tabular}{|c|c|c|c|}
\hline \multirow[b]{2}{*}{ Weight fraction of SiC, wt.\% } & \multirow[b]{2}{*}{ Aging time, $h$} & \\
\hline & & Solutionizing temperature, $495^{\circ} \mathrm{C}$ & Solutionizing temperature, $530{ }^{\circ} \mathrm{C}$ \\
\hline \multirow[t]{4}{*}{0} & 0 & 55 & 51 \\
\hline & 4 & 52 & 34 \\
\hline & 12 & 58 & 35 \\
\hline & 24 & 61 & 30 \\
\hline \multirow[t]{4}{*}{2.5} & 0 & 61 & 65 \\
\hline & 4 & 62 & 75 \\
\hline & 12 & 61 & 66 \\
\hline & 24 & 60 & 69 \\
\hline \multirow[t]{4}{*}{5} & 0 & 69 & 68 \\
\hline & 4 & 72 & 91 \\
\hline & 12 & 86 & 110 \\
\hline & 24 & 88 & 70 \\
\hline \multirow[t]{4}{*}{7.5} & 0 & 76 & 69 \\
\hline & 4 & 84 & 66 \\
\hline & 12 & 98 & 78 \\
\hline & 24 & 103 & 73 \\
\hline
\end{tabular}

HV0.05. Extending the aging time to $24 \mathrm{~h}$ resulted in its decreasing to $70 \mathrm{HV} 0.05$ due to over aging.

Composite materials require different temperature parameters in solid-solution hardening than unreinforced $\mathrm{A} 14 \mathrm{Cu}$ matrix material. While the solution temperature equal to $495{ }^{\circ} \mathrm{C}$ is too low to further successful aging hardening of the pure $\mathrm{Al} 4 \mathrm{Cu}$ matrix, in the case of composites, thermal mismatch between the reinforcing phase and matrix leads to high dislocation density and consequently faster aging kinetics. In addition, the presence of a higher dislocation density in composites with the addition of reinforcement provides new nucleation sites for $\theta^{\prime}$ precipitation leading to a finer size of precipitates compared to those in unreinforced matrix alloy.

The aging plots correlate with the performed microstructural investigation. The number of $\mathrm{Al}_{2} \mathrm{Cu}$ precipitates increases with increasing the aging time. After 4-h aging, the number of $\mathrm{Al}_{2} \mathrm{Cu}$ precipitates is smaller, which corresponds to the lower microhardness of the composites. Instead, the large amount of $\mathrm{Al}_{2} \mathrm{Cu}$ precipitant with fine size accounts for the peak microhardness after 12-h aging of composites previously solution treated at $530{ }^{\circ} \mathrm{C}$. After $24 \mathrm{~h}$ of aging, the size of $\mathrm{Al}_{2} \mathrm{Cu}$ precipitates significantly increases, leading to a decrease in microhardness.

\section{Conclusions}

In this research work, powder metallurgy-processed $\mathrm{Al} 4 \mathrm{Cu}$ alloy composites reinforced with $\mathrm{SiC}$ particles were subjected to age hardening. The primary conclusions that can be drawn from the study are as follows:

- In the microstructure of non-heat-treated both matrix and composite materials, the grain boundaries are revealed by precipitations of coarser $\mathrm{Al}_{2} \mathrm{Cu}$ phase.

- There was a difference between the heat-treated microstructure of the matrix material and composite materials reinforced with $\mathrm{SiC}$ particles, which indicates that composite materials require different temperature parameters in solid-solution hardening than unreinforced $\mathrm{Al} 4 \mathrm{Cu}$ matrix material produced by powder metallurgy technique.

- The solution temperature equal to $495{ }^{\circ} \mathrm{C}$ is too low to successful solution treatment of the pure $\mathrm{Al} 4 \mathrm{Cu}$ matrix. There are still a lot of micron-sized particles remaining in the matrix that was not fully dissolved into the matrix.

- Applying solution temperature equal to $530{ }^{\circ} \mathrm{C}$ in solution treatment of composite materials allows for almost complete dissolution of intermetallic phase.

- The Al4Cu-5 wt.\% of SiC composite solution treated at $530{ }^{\circ} \mathrm{C}$ shows the highest increment in microhardness by aging treatment. After 12-h aging treatment, numerous nanosized $\mathrm{Al}_{2} \mathrm{Cu}$ phases uniformly distributed in the matrix inhibit the dislocation movement and account for the peak microhardness (110 HV0.05).

\section{Acknowledgments}

The financial support of the Polish State Committee for Scientific Research under the Grant Number 16.16.180.006 is kindly acknowledged.

\section{Open Access}

This article is licensed under a Creative Commons Attribution 4.0 International License, which permits use, sharing, adaptation, distribution and reproduction in any medium or format, as long as you give appropriate credit to the original author(s) and the source, provide a link to the Creative Commons licence, and indicate if changes were made. The images or other third party material in this article are included in the article's Creative Commons licence, unless indicated otherwise in a credit line to the material. If material is not included in the article's Creative Commons licence and your intended use is not permitted by statutory regulation or exceeds the permitted use, you will need to obtain permission directly from the copyright holder. To view a copy of this licence, visit http://creativecommons.org/licenses/by/4.0/. 


\section{References}

1. M. Gupta, L. Lu, and S.E. Ang, Effect of Microstructural Features on the Ageing Behaviour of $\mathrm{Al}-\mathrm{Cu} / \mathrm{SiC}$ Metal Matrix Composites Processed Using Casting and Rheocasting Routes, J. Mater. Sci., 1997, 32, p 1261-1267 ((in English))

2. Y.P. Sun, H.G. Yan, and Z.H. Chen, Microstructures and Properties of Heat-treated 7090/SiCp Aluminum Matrix Composite, Chin. J. Nonferrous Met., 2008, 18(5), p 829-833 ((in English))

3. L. Pei, W. Aiqin, X. Jingpei, and H. Shiming, Effect of Heat Treatment on Microstructure and Mechanical Properties of SiCp/2024 Aluminum Matrix Composite, J. Wuhan Univ. Technol. Mater. Sci. Ed., 2015, 30(6), p 1229-1233 ((in English))

4. S.L. Dong, J.F. Mao, D.Z. Yang, Y.X. Cui, and L.T. Jiang, AgeHardening Behavior of a SiCw/Al- Li-Cu-Mg-Zr Composite, Jiang. Mater Sci, 2002, A327, p 213-223 ((in English))

5. V.K. Varma, Y.R. Mahajan, and V.V. Kutumbarao, Ageing Behaviour of Al-Cu-Mg Alloy Matrix Composites with SiCp of Varying Sizes, Scr. Mater., 1997, 37, p 485-489 ((in English))

6. S. Suresh, T. Christman, and Y. Sugimura, Accelerated Aging in Cast Al Alloy-SiC Particulate Composites, Scr. Mater., 1989, 23, p 1599 1602 ((in English))

7. T.S. Kim, T.H. Kim, K.H. Oh, and H.I. Lee, Suppression of $\theta^{\prime \prime}$ Formation in the $\mathrm{SiC}$ Whiskerreinforced Al-4 wt.\% Cu Composites, $J$. Mater. Sci., 1992, 27, p 2599-2605 ((in English))

8. B. Dutta and M.K. Surappa, Age-Hardening Behaviour of Al-Cu-SiCp Composites Synthesized by Casting Route, Scr. Metall. Mater., 1995, 32(5), p 731-736 ((in English))

9. S. Sharma, T. Nanda, and O.P. Pandey, Investigation of T4 and T6 Heat Treatment on the Wear Properties of Sillimanite Reinforced LM30 Aluminium Alloy Composites, Wear, 2019, 426-427(Part A), p 27-36 ((in English))

10. H.K. Durmus and C. Meric, Age-Hardening Behavior of Powder Metallurgy AA2014 Alloy, Mater. Des., 2007, 28, p 982-986 ((in English))

11. A. Badkul, N. Jha, D.P.D. Mondal, S. Das, and M.S. Yadav, Age Hardening Behaviour of 2014 Al Alloy-SiC Composites: Effect of Porosity and Strontium Addition, Indian J. Eng. Mater. Sci., 2014, 2011(18), p 79-85 ((in English))
12. F. Bedir, Characteristic Properties of $\mathrm{Al}-\mathrm{Cu}-\mathrm{SiCp}$ and $\mathrm{Al}-\mathrm{Cu}-\mathrm{B} 4 \mathrm{Cp}$ Composites Produced by Hot Pressing Method Under Nitrogen Atmosphere, Mater. Des., 2007, 28, p 1238-1244 ((in English))

13. T. Pieczonka, Powder Metallurgy Processing of Aluminium. In: Polish metallurgy 20062010 in time of the worldwide economic crisis/ed. K. Świątkowski. Committee of Metallurgy of the Polish Academy of Sciences. Kraków: Publishing House "AKAPIT”, 2010, p 37-57 (in English)

14. A. Łatkowski and J. Jarominek, Metaloznawstwo metali nieżelaznych. Course Books 1371: AGH University of Science and Technology Press, 1994, p 42-62 (in Polish)

15. S. Aribo, J.A. Omotoyinbo, and D.O. Folorunso, High Temperature Mechanical Properties of Silicon Carbide Particulate Reinforced Cast Aluminum Alloy Composite, Leonardo Electron. J. Pract. Technol., 2011, 18, p 9-16 ((in English))

16. S.W. Kim, U.J. Lee, S.W. Han, D.K. Kim, and K. Ogi, Heat Treatment and Wear Characteristics of Al/SiCp Composites Fabricated by Duplex Process, Compos. B, 2003, 34(8), p 737-745 ((in English))

17. K.K. Chawla, A.H. Esmaeili, A.K. Datye, and A.K. Vasudevan, Effect of Homogeneous/Heterogeneous Precipitation on Aging Behaviour of SiCp/AI, 2014 Composite, Scr. Metall. Mater., 1991, 25, p 1315-1319 ((in English))

18. H.R. Lashgari, S. Zaneneh, H. Shahmir, M. Saghafi, and M. Emamy, Heat Treatment Effect on the Microstructure, Tensile Properties and Dry Sliding Wear Behavior of A356-10\%B4C Cast Composites, Mater. Des., 2010, 31, p 4414-4422 ((in English))

19. M. Tiryakioglu, The Effect of Solution Treatment and Artificial Aging on the Work Hardening Characteristics of a Cast Al-7\% $\% \mathrm{Si}-0.6 \% \mathrm{Mg}$ Alloy, Mater. Sci. Eng. A, 2006, 427, p 154-159 ((in English))

20. Y. Altunpak, S. Aslan, M.O. Güler, and H. Akbulut, Effect of Alternative Heat-Treatment Parameters on the Aging Behavior of Short-Fiber-Reinforced 2124 Al Composites, Mater. Technol., 2016, 50, p 1011-1016 ((in English))

Publisher's Note Springer Nature remains neutral with regard to jurisdictional claims in published maps and institutional affiliations. 